\title{
Accuracy of portable devices in measuring peak cough flow
}

\begin{tabular}{|c|c|}
\hline Journal: & Physiological Measurement \\
\hline Manuscript ID: & PMEA-100401 \\
\hline Manuscript Type: & Paper \\
\hline Date Submitted by the Author: & 18-Jun-2014 \\
\hline Complete List of Authors: & $\begin{array}{l}\text { Kulnik, Stefan; King's College London, Department of Clinical Neuroscience } \\
\text { MacBean, Victoria; King's College London, Department of Respiratory } \\
\text { Medicine and Allergy } \\
\text { Birring, Surinder; King's College London, Department of Respiratory } \\
\text { Medicine and Allergy } \\
\text { Moxham, John; King's College London, Department of Respiratory Medicine } \\
\text { and Allergy } \\
\text { Rafferty, Gerrard; King's College London, Department of Respiratory } \\
\text { Medicine and Allergy } \\
\text { Kalra, Lalit; King's College London, Department of Clinical Neuroscience }\end{array}$ \\
\hline Article Keywords: & $\begin{array}{l}\text { peak cough flow, accuracy, peak flow meter, spirometer, } \\
\text { pneumotachograph }\end{array}$ \\
\hline Abstract: & $\begin{array}{l}\text { Peak cough flow (PCF) measurements can be used as indicators of cough } \\
\text { effectiveness. Portable peak flow meters and spirometers have been used } \\
\text { to measure PCF, but little is known about their accuracy compared to } \\
\text { laboratory based pneumotachograph systems. We compared the accuracy } \\
\text { of four portable devices (Mini-Wright and Assess peak flow meters, } \\
\text { SpiroUSB and Microlab spirometers) in measuring PCF with a calibrated } \\
\text { laboratory based pneumotachograph system. Twenty healthy volunteers } \\
\text { (mean (SD) age } 45 \text { (16)) coughed through a pneumotachograph connected } \\
\text { in series with each portable device in turn, and the difference in PCF } \\
\text { readings was analysed. In addition, mechanically generated flow waves of } \\
\text { constant peak flow were delivered through each device both independently } \\
\text { and when connected in series with the pneumotachograph. Agreement } \\
\text { between PCF readings obtained with the pneumotachograph and the } \\
\text { portable devices was poor. Peak flow readings were lower when measured } \\
\text { using the portable devices, for both volitional coughs and mechanically } \\
\text { generated flow waves; 95\% limits of agreement spanned approximately } \\
150 \text { L/min. Of the four portable devices examined none were sufficiently } \\
\text { accurate for the measurement of PCF. Depending on the measurement } \\
\text { method used, absolute values of PCF reported in the literature may not be } \\
\text { directly comparable. }\end{array}$ \\
\hline
\end{tabular}


Title (57 characters with spaces):

Accuracy of Portable Devices in Measuring Peak Cough Flow

Authors:

Stefan Tino Kulnik ${ }^{1}$, Victoria MacBean ${ }^{2}$, Surinder Singh Birring ${ }^{2}$, John Moxham², Gerrard Francis Rafferty $^{2}$, Lalit Kalra ${ }^{1}$

${ }^{1}$ Stroke Research Team, Department of Clinical Neuroscience, Institute of Psychiatry, King's College London, PO Box 41, Denmark Hill, London, SE5 8AF, United Kingdom, Tel: +44 (0)20 32997784 , Fax: +44 (0)20 3299 5864, Email: stefan.s.kulnik@kcl.ac.uk

${ }^{2}$ Department of Respiratory Medicine and Allergy, Division of Asthma, Allergy \& Lung Biology, School of Medicine, King's College London, Chest Unit, $1^{\text {st }}$ Floor Cheyne Wing, King's College Hospital, Denmark Hill, London, SE5 9RS, United Kingdom

Short title/running head (57 characters with spaces) Accuracy of Portable Devices in Measuring Peak Cough Flow

\begin{abstract}
(196 words):
Peak cough flow (PCF) measurements can be used as indicators of cough effectiveness. Portable peak flow meters and spirometers have been used to measure PCF, but little is known about their accuracy compared to laboratory based pneumotachograph systems. We compared the accuracy of four portable devices (Mini-Wright and Assess peak flow meters, SpiroUSB and Microlab spirometers) in measuring PCF with a calibrated laboratory based pneumotachograph system. Twenty healthy volunteers (mean (SD) age 45 (16)) coughed through a pneumotachograph connected in series with each portable device in turn, and the difference in PCF readings was analysed. In addition, mechanically generated flow waves of constant peak flow were delivered through each device both independently and when connected in series with the pneumotachograph. Agreement between PCF readings obtained with the pneumotachograph and the portable devices was poor. Peak flow readings were lower when measured using the portable devices, for both volitional coughs and mechanically
\end{abstract}


generated flow waves; $95 \%$ limits of agreement spanned approximately $150 \mathrm{~L} / \mathrm{min}$. Of the four portable devices examined none were sufficiently accurate for the measurement of PCF. Depending on the measurement method used, absolute values of PCF reported in the literature may not be directly comparable.

Key words: Peak cough flow; accuracy; peak flow meter; spirometer; pneumotachograph

Submitted to:

Physiological Measurement

PACS Classification:

06: Metrology, measurements and laboratory procedures 
Main text (2,738 words)

\section{Introduction}

Cough flow testing is useful as an outcome measure in research and a monitoring or diagnostic tool in clinical practice. Peak cough flow (PCF) is commonly used as an indicator of the strength or effectiveness of cough, particularly in clinical populations with neuromuscular impairment (Jones et al 2012). Cough can be accurately quantified using laboratory pneumotachograph based systems as described by Singh et al (1994), but these can often consist of several components, can be expensive, not easily transportable, and require significant knowledge by the user for correct operation. Practical devices, which can conveniently be applied in clinical settings, patients' homes or other community locations, may be of use to clinicians and researchers. In several clinical studies, standard peak flow meters and hand-held spirometers have been used to measure PCF (Table 1) (LoMauro et al 2014, Silverman et al 2014, Cleary et al 2013, Kimura et al 2013, Lee et al 2013, Cardoso et al 2012, Freitas et al 2010, Brito et al 2009, Fiore et al 2008, Daftary et al 2007, Sancho et al 2007, Bach et al 2006, Dohna-Schwake et al 2006, Kang et al 2006, Gauld and Boynton 2005, Sancho et al 2004, Suarez et al 2002, Bach et al 1997, Bach and Saporito 1996, Bach 1995, Leiner et al 1966, Wright and McKerrow 1959). These devices are designed to measure peak flow during a forced expiratory manoeuvre, and their accuracy in measuring peak flow during cough is uncertain.

In the present study we examined the accuracy of two commonly used peak flow meters and two hand-held spirometers when measuring PCF compared with a laboratory pneumotachograph based measurement system.

\section{Materials and Methods}

\subsection{Study subjects}

Healthy volunteers with no medical history of respiratory disease or conditions affecting the anatomy and function of the upper airway who were comfortable coughing repeatedly over a short period of time were recruited. The study had ethical approval from the Psychiatry, Nursing and Midwifery 
Research Ethics Committee at King's College London, United Kingdom (study reference $\mathrm{PNM} / 12 / 13-143)$. All participants gave written informed consent.

\subsection{Study design}

Four hand-held devices were compared to a laboratory pneumotachograph based flow measurement system: the Mini-Wright Standard peak flow meter (European Union (EU) Scale, range 60-800 L/min, accuracy $\pm 10 \%$ or $10 \mathrm{~L} / \mathrm{min}$ according to manufacturer, Clement Clarke International, Harlow, England); Assess peak flow meter (range $60-880 \mathrm{~L} / \mathrm{min}$, accuracy $\pm 10 \%$ or $20 \mathrm{~L} / \mathrm{min}$ according to manufacturer, Philips Respironics, Pittsburgh, Pennsylvania); SpiroUSB turbine spirometer, (range $12-900 \mathrm{~L} / \mathrm{min}$, accuracy $\pm 3 \%$ according to manufacturer, CareFusion, San Diego, California); and the Microlab turbine spirometer, (range $12-900 \mathrm{~L} / \mathrm{min}$, accuracy $\pm 3 \%$ according to manufacturer, CareFusion, San Diego, California). These four devices were selected as they are produced by leading manufacturers and frequently used in clinical practice.

The devices under test were attached individually to a Fleisch-type pneumotachograph (ID $4.4 \mathrm{~cm}$, length $6.0 \mathrm{~cm}$, PK Morgan Ltd, Rainham, England). Differential pressure was measured using a Validyne differential pressure transducer (MP45, range $\pm 2 \mathrm{cmH}_{2} \mathrm{O}$, Validyne Engineering, Northridge, California) and the signal amplified (CD15, Validyne Engineering, Northridge, California) and acquired on a laptop running LabChart software (LabChart Pro, version 7.2.2, ADInstruments Ltd, Oxford, England) with analog-to-digital sampling of $2 \mathrm{kHz}$ (PowerLab/16SP, ADInstruments Ltd, Oxford, England). The pneumotachograph system was linear in the flow range 0$700 \mathrm{~L} / \mathrm{min}\left(\mathrm{R}^{2}=0.999845\right)$ and had a frequency response of $50 \mathrm{~Hz}$. A two-point calibration was performed at the beginning of each testing session, using a rotameter (InFlux OF1"S, 60-600 L/min flow, Techniquip Ltd, Taunton, England).

\subsection{Methods}

A bacterial filter (Spiroguard Standard, Air Safety Medical, Morecambe, England), the pneumotachograph and one portable device were connected in series. Participants were instructed to 
cough through the filter so that the peak flow of each cough was measured by the pneumotachograph system and the portable device. The portable devices were tested in a random order and were always connected downstream from the pneumotachograph. The calibration of the SpiroUSB and the Microlab turbine spirometers was verified with a 3 litre calibration syringe at the beginning of each testing session as per manufacturer's recommendation. For each device, volunteers were instructed to produce five strong coughs (from total lung capacity), five weak coughs (from residual volume) and five coughs of subjectively moderate strength (between strong and weak cough efforts). Participants were seated during testing. Altogether, 300 coughs were measured per portable device.

Volunteers also performed spirometric forced expiratory manoeuvres through the pneumotachograph with each portable device connected in series in random order. One hundred maximal and 100 subjectively submaximal forced expiratory manoeuvres were measured per portable device, giving a range of expiratory flows during forced expiration without glottic closure.

In order to control for any systematic effect on cough flow measurements caused by the in-series connection of pneumotachograph and alternative device, flow waves of consistent peak flow were mechanically generated using a 50 L pressure vessel (Medical Engineering Department, Royal Brompton Hospital, London, England) connected to a balloon occlusion valve (Medical Engineering Department, Royal Brompton Hospital, London, England). The barrel was pressurised with compressed air to a predetermined pressure, monitored with a digital manometer (C9553 Pressure Meter, Comark, Norwich, England), at which point the occlusion valve was opened and a burst of short duration airflow released. The consistency of peak flow for these flow bursts was confirmed with five consecutive measurements with the pneumotachograph system. Vessel pressures of 5, 10, $15,20,30$ and $40 \mathrm{cmH}_{2} \mathrm{O}$ were used, resulting in bursts of airflow with mean (SD) peak flows of 138 (0.4), 250 (1.3), 343 (0.8), 422 (0.8), 559 (1.6) and 684 (2.9) L/min, respectively. Using the mechanically produced airflows, the agreement of peak flow measurements between systems was deteremined with the pneumotachograph and alternative devices connected in series (identical setup as used for volunteers, including bacterial filter); and with pneumotachograph and alternative devices connected in isolation (including bacterial filter). Five measurements were made at each flow level for each portable device connected in series and in isolation. 


\subsection{Analysis}

Data were analysed using statistical software (Stata version 12.1, StataCorp LP, College Station, Texas). Bland-Altman analysis was used to compare peak flow measurements obtained from the pneumotachograph and each device for both measurements of volitional PCF, peak flow obtained from forced expiratory manoeuvres and the mechanically generated flow waves with devices used in series and in isolation.

\section{Results}

Twenty volunteers, mean (SD) age 45 (16), were studied, with at least one female and one male participant per age decade. The mean differences and 95\% limits of agreement for volunteers' PCF obtained with the pneumotachograph system and the four portable devices are summarised in Table 2 . Bland-Altman analysis indicated that measurements of PCF were lower with the devices tested compared with the pneumotachograph system (Figure 1). Measurements of PCF were markedly lower using the Mini-Wright peak flow meter (mean (95\% limits of agreement) bias $56 \mathrm{~L} / \mathrm{min}$ (-26 to 138 $\mathrm{L} / \mathrm{min}$ )) (Figure 1a), with the difference increasing with increasing PCF (Spearman's rank correlation coefficient $\left.r_{s}=0.38, p<0.0001\right)$. Despite a small overall mean ( $95 \%$ limits of agreement) bias of 3 $\mathrm{L} / \mathrm{min}$ (-76 to $82 \mathrm{~L} / \mathrm{min}$ ) across the range (Figure $1 \mathrm{~b}$ ), PCFs measured using the Assess device were lower than the pneumotachograph system at low PCF and higher at high PCF $\left(\mathrm{r}_{\mathrm{s}}=-0.46, \mathrm{p}<0.0001\right)$. Both the SpiroUSB (mean (95\% limits of agreement) bias $50 \mathrm{~L} / \mathrm{min}$ (-26 to $125 \mathrm{~L} / \mathrm{min})$ ) (Figure 1c) and the Microlab spirometers (mean (95\% limits of agreement) bias $55 \mathrm{~L} / \mathrm{min}$ (-23 to $132 \mathrm{~L} / \mathrm{min})$ ) (Figure 1d) returned PCF readings that were consistently lower than those measured using the pneumotachograph system.

Some coughs with low peak flows were not registered by the portable devices and were excluded from the Bland Altman analysis. The Mini-Wright and Assess peak flow meters did not register 15 coughs with PCF between $60 \mathrm{~L} / \mathrm{min}$ (lowest mark on the devices' scale) and $118 \mathrm{~L} / \mathrm{min}$, as measured by the pneumotachograph. Thirty-four coughs with PCF from 89 to $207 \mathrm{~L} / \mathrm{min}$ were not registered by 
the SpiroUSB spirometer. Twenty-five coughs with PCF from 58 to $237 \mathrm{~L} / \mathrm{min}$ were not registered by the Microlab spirometer.

The results for the mechanically generated flow waves are presented in Tables 3 and 4 and in Figure 2. Example traces of mechanically generated flow waves in comparison with human cough flow waves are given in Figure 3. All portable devices recorded lower peak flow compared to the pneumotachograph system regardless of whether measurements were made when connected in series (Table 3) or in isolation (Table 4). The differences in measured peak flow between the pneumotachograph and alternative devices were smaller when the instruments were connected in series; and larger when the instruments were used in isolation. When instruments were connected in series, the pneumotachograph and portable devices all gave lower peak flow readings compared to when instruments were used in isolation; whereby measurements were always reduced to a greater extent for the pneumotachograph (mean (SD) difference 79 (38) L/min) than for the portable devices (mean (SD) difference 9 (6) L/min).

Correlation analysis to examine the relationship between cough rise time (time from initiation of positive flow to peak flow) and the degree of inaccuracy indicated statistically significant weak inverse correlations for the Mini-Wright $\left(\mathrm{r}_{\mathrm{s}}=-0.29, \mathrm{p}<0.0001\right)$ and the Assess peak flow meter $\left(\mathrm{r}_{\mathrm{s}}=\right.$ $0.28, \mathrm{p}<0.0001)$; and statistically significant moderate inverse correlations for the SpiroUSB $\left(\mathrm{r}_{\mathrm{s}}=\right.$ $0.68, \mathrm{p}<0.0001)$ and the Microlab spirometer $\left(\mathrm{r}_{\mathrm{s}}=-0.55, \mathrm{p}<0.0001\right)$ (Figure 4).

Bland-Altman analysis of peak flow measurements during spirometric forced expiratory manoeuvres performed with each device connected in series with the pneumotachograph demonstrated a smaller bias and narrower limits of agreement compared to those for PCF (Table 5, Figure 5). Similar weak and moderate correlations between time to peak flow and the degree of inaccuracy were observed: $r_{s}=$ $-0.34(\mathrm{p}<0.0001)$ Mini-Wright peak flow meter, $\mathrm{r}_{\mathrm{s}}=0.16(\mathrm{p}=0.021)$ Assess peak flow meter, $\mathrm{r}_{\mathrm{s}}=-0.56$ $(p<0.0001)$ SpiroUSB spirometer, $r_{s}=-0.66(p<0.0001)$ Microlab spirometer (Figure 6).

\section{Discussion}


The results of this study indicate that when compared to a laboratory pneumotachograph based measurement system, four portable clinical flow measurement devices were inaccurate when measuring cough peak flows and returned lower PCF readings. These differences are clinically relevant when compared with the magnitude of PCF measurements in clinical populations. In addition, some low flow coughs were not registered by these devices, which impacts on their utility in very weak or severely obstructed patient populations.

The advantage of a compact, portable and practical clinical flow measurement device over a complex pneumotachograph system for the purpose of clinical practice and research is self-evident. This is particularly true for clinical populations with neuromuscular conditions, where mobility and transportation can be problematic. However, it should not be assumed that portable peak flow meters and hand-held spirometers are accurate when used for PCF measurement, as these devices are designed to measure peak flow during a forced expiratory manoeuvre. In our measurements of mechanically generated flow waves, the portable devices under test showed good instrument repeatability, with small standard deviations at each level of flow. It could be argued that good instrument repeatability justifies the use of these devices in studies with repeated measures designs. However, the accuracy of PCF measurements becomes particularly problematic when patients are assessed against absolute thresholds. Clinical guidelines cite PCF thresholds of $160 \mathrm{~L} / \mathrm{min}$ and 270 L/min to direct clinical care of patients with neuromuscular conditions (Bott et al 2009, American Thoracic Society 2004). A scenario can be envisaged whereby the PCF measured for a patient could lie on either side of these threshold values, depending on the measurement device used. Our data highlights the importance of considering which measurement device was used to measure PCF when interpreting values.

The Mini-Wright and Assess peak flow meters have been used previously for PCF measurement in clinical studies (Table 1). The Assess peak flow meter (formerly Access Model 710, Health Scan Products Inc, Cedar Grove, New Jersey) was used in the frequently cited clinical studies by Bach and collaborators (Bach et al 1997, Bach and Saporito 1996, Bach 1995). To our knowledge, the 
SpiroUSB and Microlab spirometers have not previously been used for PCF measurement in clinical studies, but a similar turbine-based hand-held spirometer (Spirobank, Medical International Research, Rome, Italy) was used in the study by Fiore et al (2008).

Sancho et al (2004) and Silverman et al (2014) have both previously examined the accuracy of different portable devices for cough flow testing using repeated maximal cough efforts. This method, however, presumes that repeated coughs are sufficiently consistent for intra-subject variability to be ignored. Although intra-subject variability may be accounted for by randomising the order of devices, and by obtaining repeated measurements within a certain range, for example three maximal coughs within 5\% PCF as in the study by Sancho et al, intra-subject variability due to fatigue, discomfort, motivation, or practice effect remains a limitation of this method, especially with increasing number of repetitions. Also, measurements across the mid and lower range of potential values may not be assessed conveniently using maximal efforts. The method applied in our study, connecting two devices in series, eliminated the problem of intra-subject variability, and allowed the direct comparison of coughs across a range of PCF values.

Using mechanically generated flow waves, simulating human expiratory flow waves with consistent peak flows, has been used previously to test spirometers and peak flow meters (Miller et al 2005, 2003). Such an approach allows comparison of measurement devices without the influence of intrasubject variability or bias due to in-series connection of instruments. The mechanical testing system employed in the current study produced flow waves with peak flows and rise times within the range observed in human coughs (Sivasothy et al 2001) and indicated greater inaccuracy of PCF measurements when using the four devices in isolation. The smaller differences in PCF observed with the in series setup is most likely the result of increased air flow resistance causing greater relative reductions in pneumotachograph PCF measurements. It is likely, therefore, that the differences in PCF measurements between the pneumotachograph and portable devices during coughs in the healthy human subjects were also underestimated. 
In cough, the time to peak flow (rise time) is shorter than during a forced expiratory manoeuvre (Miller et al 2002, Sivasothy et al 2001). We theorized that this short rise time may be the critical characteristic causing inaccuracies in measurement, as peak flow meters and hand-held spirometers may not respond adequately to such a rapid change in signal. Thus, increasing inaccuracy could be expected with shorter cough rise time. Our data partly supports this theory. There was a correlation of weak to moderate strength between cough rise time and the inaccuracy in PCF in our human volunteers. Similarly, more consistent agreement could be expected for peak flow measurements during forced expiratory manoeuvres than during cough, since the portable devices were designed for peak flow measurements during forced expiratory manoeuvres. Better agreement was demonstrated for peak flow measurements during forced expiratory manoeuvres, more so for the two spirometers and the Assess peak flow meter than for the Mini-Wright peak flow meter. The $95 \%$ limits of agreement were also narrower than for PCF measurements, but still spanned approximately $90 \mathrm{~L} / \mathrm{min}$ for all four portable devices. Of note, the accuracy of hand-held peak flow meters in measuring peak flow during forced expiratory manoeuvres has been investigated by others, with devices performing variably (Miller et al 2003, Folgering et al 1998). We suggest that rise time is one factor influencing accuracy of peak flow measurements, but that further interactions between characteristics of human cough and properties of measurement devices impact on the performance of instruments. This identifies an interesting area for further investigation.

In order to advance cough flow measurement in clinical research, recommendations based on a consensus statement would be of benefit, similar to those produced for the measurement of cough frequency and reflex cough sensitivity (Morice et al 2007). Clearly, there is a demand for technology that enables scientifically accurate, but also practical and convenient measurement of cough flow. Developers of measurement devices should consider the research and clinical conditions such devices are likely to be applied in.

\section{Conclusions}


In conclusion, the four portable flow measurement devices examined in our study did not accurately measure PCF. It is important to recognise that, depending on the measurement instrument, absolute values of PCF reported in the literature may not be directly comparable. Similarly, peak flow meters and hand-held spirometers should be used with caution when measuring PCF in clinical practice, particularly in respect to directing patient management.

\section{Acknowledgements}

This article presents independent research funded by the United Kingdom National Institute for Health Research (NIHR) under its Research for Patient Benefit (RfPB) Programme (Grant Reference Number PB-PG-0408-16096). The views expressed are those of the authors and not necessarily those of the National Health Service (NHS), the NIHR or the Department of Health. The authors declare that no potential conflicting interests exist with any companies/organisations whose products may be discussed in this article.

\section{References}

American Thoracic Society 2004 Respiratory care of the patient with Duchenne muscular dystrophy Am. J. Respir. Crit. Care Med. 170 456-65

Bach J R, Goncalves M R, Paez S, Winck J C, Leitao S and Abreu P 2006 Expiratory flow maneuvers in patients with neuromuscular diseases Am. J. Phys. Med. Rehabil. 85 105-1

Bach J R, Ishikawa Y and Kim H 1997 Prevention of pulmonary morbidity for patients with Duchenne muscular dystrophy Chest 112 1024-8

Bach J R and Saporito L R 1996 Criteria for extubation and tracheostomy tube removal for patients with ventilatory failure: A different approach to weaning Chest 110 1566-71

Bach J R 1995 Amyotrophic lateral sclerosis: Predictors for prolongation of life by noninvasive respiratory aids Arch. Phys. Med. Rehabil. 76 828-32

Bland J M and Altman D G 1999 Measuring agreement in method comparison studies Stat. Methods Med. Res. 8 135-60

Bott J, Blumenthal S, Buxton M, Ellum S, Falconer C, Garrod R, Harvey A, Hughes T, Lincoln M, Mikelsons C, Potter C, Pryor J, Rimington L, Sinfield F, Thompson C, Vaughn P and White J 2009 Guidelines for the physiotherapy management of the adult, medical, spontaneously breathing patient Thorax 64 il-i52 
Brito M F, Moreira G A, Pradella-Hallinan M and Tufik S 2009 Air stacking and chest compression increase peak cough flow in patients with Duchenne musclular dysptrophy J. Bras. Pneumol. 35 973-9

Cardoso F, de Abreu L, Raimundo R, Faustino N, Araujo S, Valenti V, Sato M, Martins S and Torquato J 2012 Evaluation of peak cough flow in Brazilian healthy adults Int. Arch. Med. 525

Cleary S, Misiaszek J E, Kalra S, Wheeler S and Johnston W 2013 The effects of lung volume recruitment on coughing and pulmonary function in patients with ALS Amyotroph. Lateral Scler. Frontotemporal Degener. 14 111-5

Daftary A S, Crisanti M, Kalra M, Wong B and Amin R 2007 Effect of long-term steroids on cough efficiency and respiratory muscle strength in patients with Duchenne muscular dystrophy Pediatrics 119 e320-4

Dohna-Schwake C, Ragette R, Teschler H, Voit T and Mellies U 2006 IPPB-assisted coughing in neuromuscular disorders Pediatr. Pulmonol. 41 551-7

Fiore J F, Chiavegato L D, Denehy L, Paisani D M and Faresin S M 2008 Do directed cough maneuvers improve cough effectiveness in the early period after open heart surgery? Effect of thoracic support and maximal inspiration on cough peak expiratory flow, cough expiratory volume, and thoracic pain Respir. care 53 1027-34

Folgering H, v d Brink W, v Heeswijk O and v Herwaarden C 1998 Eleven peak flow meters: a clinical evaluation Eur. Respir. J. 11 188-93

Freitas F S, Ibiapina C C, Alvim C G, Britto R R and Parreira V F 2010 Relationship between cough strength and functional level in elderly Braz. J. Phys. Ther. 14 470-6

Gauld L M and Boynton A 2005 Relationship between peak cough flow and spirometry in Duchenne muscular dystrophy Pediatr. Pulmonol. 39 457-60

Jones U, Enright S and Busse M 2012 Management of respiratory problems in people with neurodegenreative conditions: A narrative review Physiotherapy 98 1-12

Kang S W, Shin J C, Park C I, Moon J H, Rha D W and Cho D 2006 Relationship between inspiratory muscle strength and cough capacity in cervical spinal cord injured patients Spinal Cord $\mathbf{4 4} 242-8$

Kimura Y, Takahashi M, Wada F and Hachisuka K 2013 Differences in the peak cough flow among stroke patients with and without dysphagia $J$. UOEH 35 9-16

Lee S C, Kang S, Kim M T, Kim Y K, Chang W H and Im S H 2013 Correlation between voluntary cough and laryngeal cough reflex flows in patients with traumatic brain injury Arch. Phys. Med. Rehabil. 94 1580-3

Leiner G C, Abramowitz S, Small M J and Stenby V B 1966 Cough peak flow rate Am. J. Med. Sci. $251211-4$

LoMauro A, Romei M, D'Angelo M G and Aliverti A 2014 Determinants of cough efficiency in Duchenne muscular dystrophy Pediatr. Pulmonol. 49 357-65

Miller M R, Atkins P R and Pedersen O F 2003 Inadequate peak expiratory flow meter characteristics detected by a computerised explosive decompression device Thorax $\mathbf{5 8} 411-6$ 
Miller M R, Hankinson J, Brusasco V, Burgos F, Casaburi R, Coates A, Crapo R, Enright P, van der Grinten C P M, Gustafsson P, Jensen R, Johnson D C, MacIntyre N, McKay R, Navajas D, Pedersen O F, Pellegrino R, Viegi G and Wanger J 2005 Standardisation of spirometry Eur. Respir. J. 26 319-38

Miller M R, Lloyd J and Bright P 2002 Recording flow in the first second of a maximal forced expiratory manoeuvre: influence of frequency content Eur. Respir. J. 19 530-3

Morice A H, Fontana G A, Belvisi M G, Birring S S, Chung K F, Dicpinigaitis P V, Kastelik J A, McGarvey L P, Smith J A, Tatar M and Widdicombe J 2007 ERS guidelines on the assessment of cough Eur. Respir. J. 29 1256-76

Sancho J, Servera E, Diaz J and Marin J 2004 Comparison of peak cough flows measured by pneumotachograph and a portable peak flow meter Am. J. Phys. Med. Rehabil. 83 608-12

Sancho J, Servera E, Diaz J and Marin J 2007 Predictors of ineffective cough during a chest infection in patients with stable amyotrophic lateral sclerosis Am. J. Respir. Crit. Care Med. 175 1266-71

Silverman E P, Carnaby-Mann G, Pitts T, Davenport P, Okun M S and Sapienza C 2014 Concordance and discriminatory power of cough measurement devices for individuals with Parkinson disease Chest 145 1089-96

Singh P, Murty G E, Mahajan R P, Knights D and Aitkenhead A R 1994 The tussometer: accuracy and reproducibility Br. J. Anaesth. 73 145-8

Sivasothy P, Brown L, Smith I E and Shneerson J M 2001 Effect of manually assisted cough and mechanical insufflation on cough flow of normal subjects, patients with chronic obstructive pulmonary disease (COPD), and patients with respiratory muscle weakness Thorax 56 438-44

Suarez A A, Pessolano F A, Monteiro S G, Ferreyra G P, Capria M E, Mesa L, Dubrovsky A and De Vito E L 2002 Peak flow and peak cough flow in the evaluation of expiratory muscle weakness and bulbar impairment in patients with neuromuscular disease Am. J. Phys. Med. Rehabil. 81 506-11

Wright B M and McKerrow C B 1959 Maximum forced expiratory flow rate as a measure of ventilatory capacity BMJ 2 1041-7 
Table 1. Portable peak flow meters and spirometers used for the measurement of peak cough flow in clinical research.

\begin{tabular}{|c|c|c|}
\hline Device & Study & Study population \\
\hline \multicolumn{3}{|l|}{ Peak flow meters } \\
\hline AsmaPLAN (Vitalograph, Ennis, & LoMauro et al, & Duchenne muscular dystrophy \\
\hline \multirow[t]{3}{*}{ Ireland) } & 2014 & \\
\hline & Sancho et al, & Neuromuscular disease, healthy \\
\hline & 2004 & subjects \\
\hline Assess (Philips Respironics, & Cleary et al, 2013 & Amyotrophic lateral sclerosis \\
\hline \multirow[t]{7}{*}{ Pittsburgh, Pennsylvania) ${ }^{a}$} & Bach et al, 2006 & Restrictive pulmonary syndrome due \\
\hline & & to neuromuscular disease \\
\hline & Kang et al, 2006 & Cervical spinal cord injury \\
\hline & Bach et al 1997 & Duchenne muscular dystrophy \\
\hline & Bach and Saporito & Spinal cord injury, progressive \\
\hline & 1996 & neuromuscular disease \\
\hline & Bach 1995 & Amyotrophic lateral sclerosis \\
\hline Astech (Astech, New York, New & Daftary et al, & Duchenne muscular dystrophy \\
\hline York) & 2007 & \\
\hline MicroPeak (Micro Medical Ltd, & Lee et al, 2013 & Traumatic brain injury, healthy \\
\hline Rochester, England) & & subjects \\
\hline Mini-Wright (Clement Clarke & Silverman et al, & Healthy subjects, Parkinson's disease \\
\hline \multirow[t]{5}{*}{ International, Harlow, England) } & 2014 & \\
\hline & Cardoso et al, & Healthy subjects \\
\hline & 2012 & \\
\hline & Freitas et al, 2010 & Healthy elderly subjects \\
\hline & Brito et al, 2009 & Duchenne muscular dystrophy \\
\hline Mini-Wright DIGITAL & Silver man et al, & Healthy subjects, Parkinson's disease \\
\hline
\end{tabular}


Table 2. Coughs from healthy volunteers: Agreement between peak cough flow measurements (Bland-Altman method of analysis) comparing four clinical flow measurement devices with the pneumotachograph measurement system.

\begin{tabular}{|c|c|c|c|}
\hline Measurement device & $\mathrm{n}^{\mathrm{a}}$ & $\begin{array}{c}\text { Mean difference from } \\
\text { pneumotachograph (bias) } \\
\text { L/min }\end{array}$ & $\begin{array}{l}95 \% \text { limits of agreement } \\
\text { L/min }\end{array}$ \\
\hline $\begin{array}{l}\text { Mini-Wright peak flow } \\
\text { meter }\end{array}$ & 291 & 56 & -26 to 138 \\
\hline Assess peak flow meter & 284 & 3 & -76 to 82 \\
\hline SpiroUSB spirometer & 266 & 50 & -26 to 125 \\
\hline Microlab spirometer & 275 & 55 & -23 to 132 \\
\hline
\end{tabular}


2

3

4

5

6

7

8

9

10

11

12

13

14

15

16

17

18

19

20

21

22

23

24

25

26

27

28

29

30

31

32

33

34

35

36

37

38

39

40

41

42

43

44

45

46

47

48

49

50

51

52

53

54

55

56

57

58

59

60

Table 3. Mechanically generated flow waves: Agreement between peak flow measurements (BlandAltman method of analysis) with four portable devices connected in series with the pneumotachograph measurement system.

\begin{tabular}{|c|c|c|c|}
\hline Measurement device & $\mathrm{n}^{\mathrm{a}}$ & $\begin{array}{c}\text { Mean difference from } \\
\text { pneumotachograph (bias) }^{b} \\
\text { L/min }\end{array}$ & $\begin{array}{l}95 \% \text { limits of agreement } \\
\text { L/min }\end{array}$ \\
\hline $\begin{array}{l}\text { Mini-Wright peak flow } \\
\text { meter }\end{array}$ & 30 & 80 & 0 to 160 \\
\hline Assess peak flow meter & 30 & 25 & 4 to 46 \\
\hline SpiroUSB spirometer & 30 & 58 & -2 to 118 \\
\hline Microlab spirometer & 30 & 54 & -5 to 113 \\
\hline
\end{tabular}


Table 4. Mechanically generated flow waves: Agreement between peak flow measurements (BlandAltman method of analysis) recorded from four portable devices and the pneumotachograph measurement system in isolation (not connected in series).

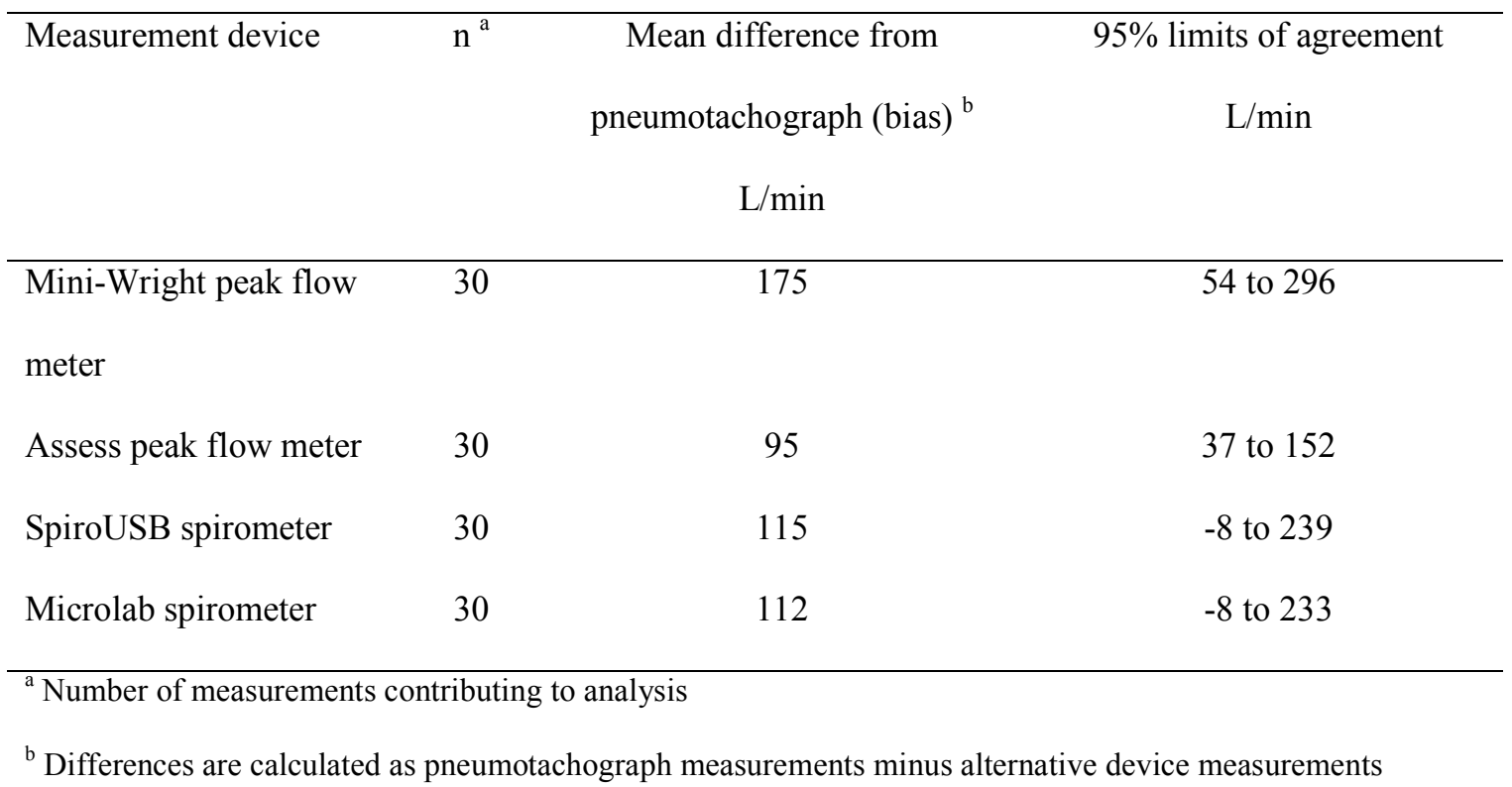


2

3

4

5

6

7

8

9

10

11

12

13

14

15

16

17

18

19

20

21

22

23

24

25

26

27

28

29

30

31

32

33

34

35

36

37

38

39

40

41

42

43

44

45

46

47

48

49

50

51

52

53

54

55

56

57

58

59

60

Table 5. Forced expiratory manoeuvres from healthy volunteers: Agreement between peak flow measurements (Bland-Altman method of analysis) comparing four clinical flow measurement devices with the pneumotachograph measurement system.

\begin{tabular}{|c|c|c|c|}
\hline Measurement device & $\mathrm{n}^{\mathrm{a}}$ & $\begin{array}{c}\text { Mean difference from } \\
\text { pneumotachograph (bias) }^{b} \\
\text { L/min }\end{array}$ & $\begin{array}{l}\text { 95\% limits of agreement } \\
\text { L/min }\end{array}$ \\
\hline $\begin{array}{l}\text { Mini-Wright peak flow } \\
\text { meter }\end{array}$ & 200 & 41 & -6 to 89 \\
\hline Assess peak flow meter & 200 & 24 & -22 to 70 \\
\hline SpiroUSB spirometer & 200 & 14 & -29 to 58 \\
\hline Microlab spirometer & 200 & 12 & -44 to 69 \\
\hline
\end{tabular}


(a) Mini-Wright

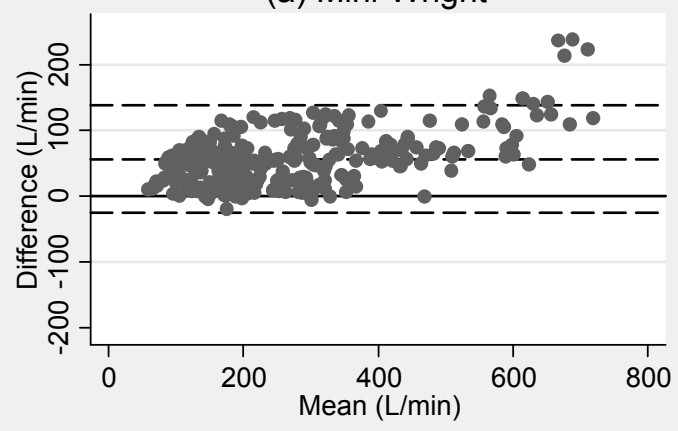

(c) SpiroUSB

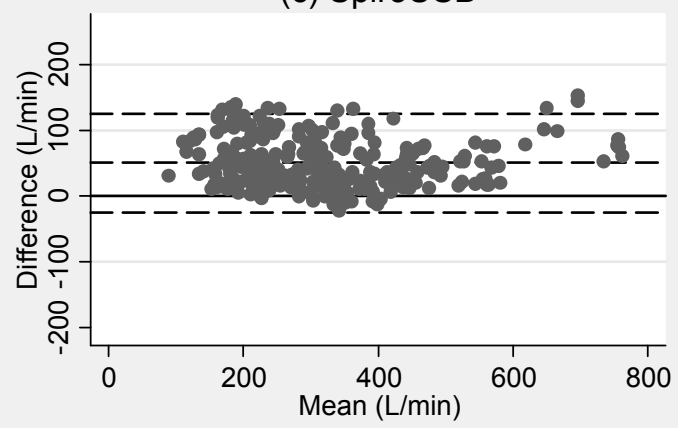

(b) Assess

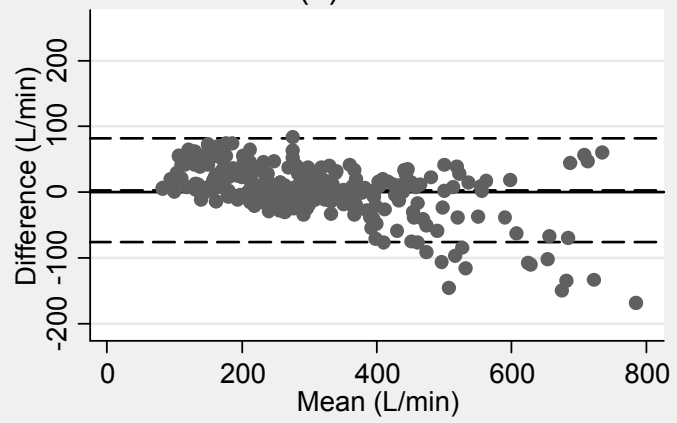

(d) Microlab

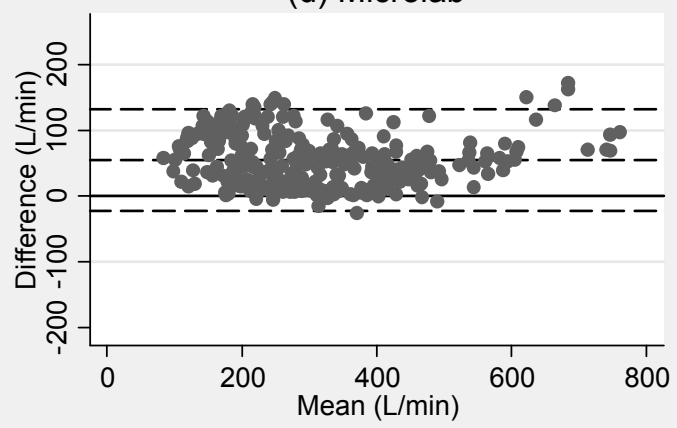

Figure 1. Coughs by healthy volunteers: Bland-Altman graphs of the agreement in measuring peak cough flow (L/min) between the pneumotachograph measurement system and (a) the Mini-Wright peak flow meter, (b) the Assess peak flow meter, (c) the SpiroUSB spirometer and (d) the Microlab spirometer. The difference between two measurements (pneumotachograph - alternative device) is plotted against the mean of two measurements. Solid lines indicate the lines of equality (no difference between measurements). Three dashed lines indicate the mean difference between measurements (bias) and the upper and lower 95\% limits of agreement (bias $\pm 1.96 \mathrm{SD})$. 

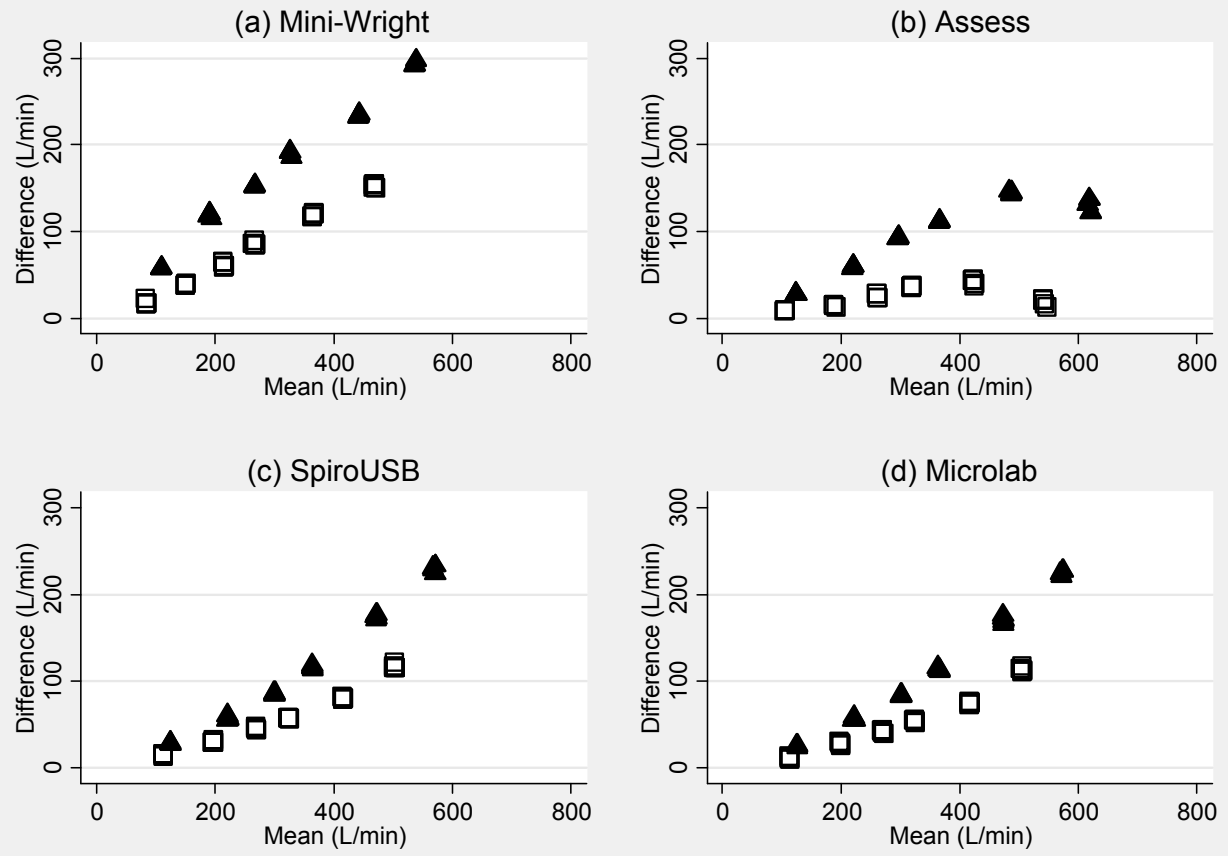

Figure 2. Mechanically generated flow waves: Agreement in measuring peak flow (L/min) between pneumotachograph and (a) Mini-Wright peak flow meter, (b) Assess peak flow meter, (c) SpiroUSB spirometer and (d) Microlab spirometer. The difference between two measurements (pneumotachograph - alternative device) is plotted against the mean of two measurements. Shown are the differences with pneumotachograph and alternative device connected in series (square markers); and measurements made with the instruments in isolation (triangular markers). 


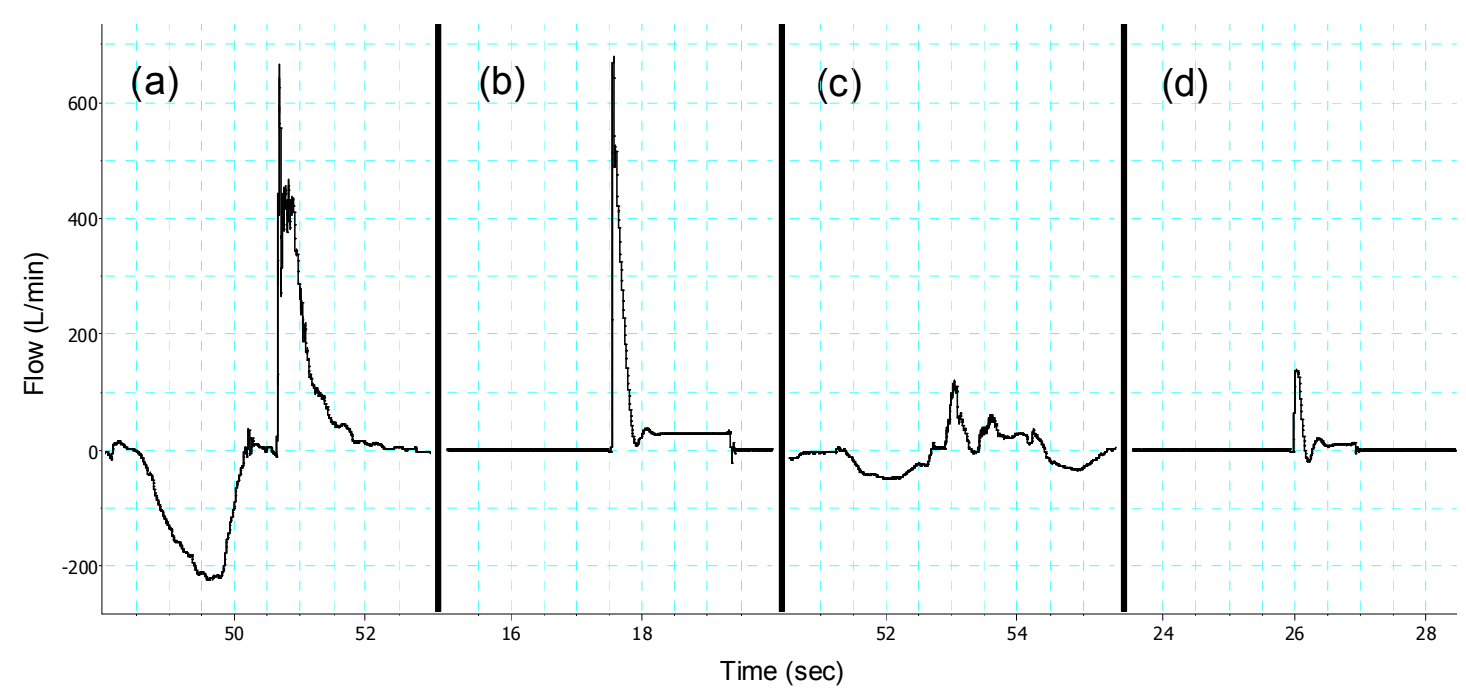

Figure 3. Examples of flow-time plots showing human coughs and mechanically generated flow waves of corresponding peak flow. (a) Maximally effortful voluntary cough from a healthy volunteer (peak cough flow $=666 \mathrm{~L} / \mathrm{min}$, rise time $=0.05 \mathrm{sec}$, volume expelled $=3.5 \mathrm{~L}$ ). (b) Mechanically generated flow burst (peak flow $=680 \mathrm{~L} / \mathrm{min}$, rise time $=0.03 \mathrm{sec}$, volume expelled $=1.6 \mathrm{~L}$ ). $(\mathrm{c})$ Maximally effortful voluntary cough from a subject with severely weakened cough following stroke (peak flow $=120 \mathrm{~L} / \mathrm{min}$, rise time $=0.14 \mathrm{sec}$, volume expelled $=0.4 \mathrm{~L})$. (d) Mechanically generated flow burst (peak flow $=138 \mathrm{~L} / \mathrm{min}$, rise time $=0.04 \mathrm{sec}$, volume expelled $=0.2 \mathrm{~L}$ ). 
(a) Mini-Wright

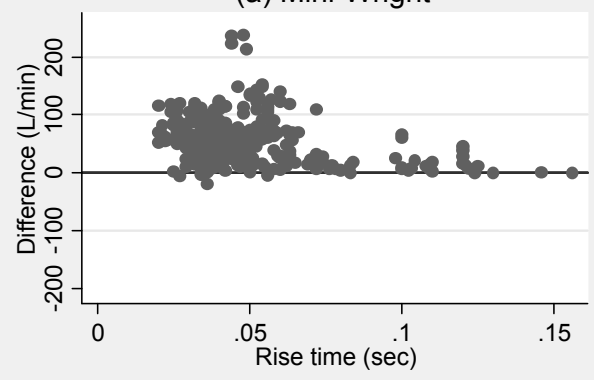

(c) SpiroUSB

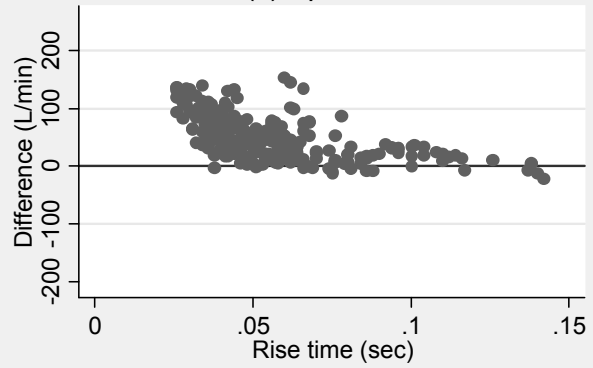

(b) Assess

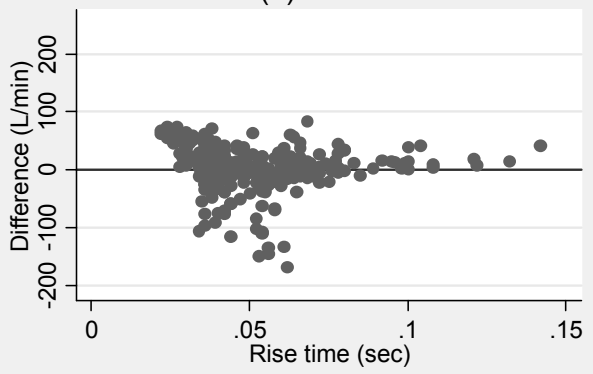

(d) Microlab

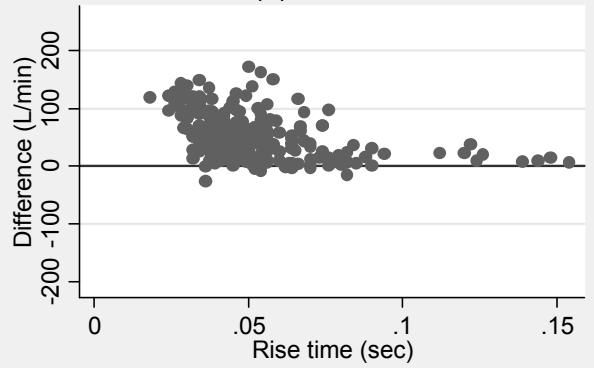

Figure 4. Coughs by healthy volunteers: The difference (pneumotachograph - alternative device) in measured peak cough flow (L/min) between pneumotachograph and (a) Mini-Wright peak flow meter, (b) Assess peak flow meter, (c) SpiroUSB spirometer and (d) Microlab spirometer is plotted against cough rise time (sec). Solid lines indicate the lines of equality (no difference between measurements). 
(a) Mini-Wright

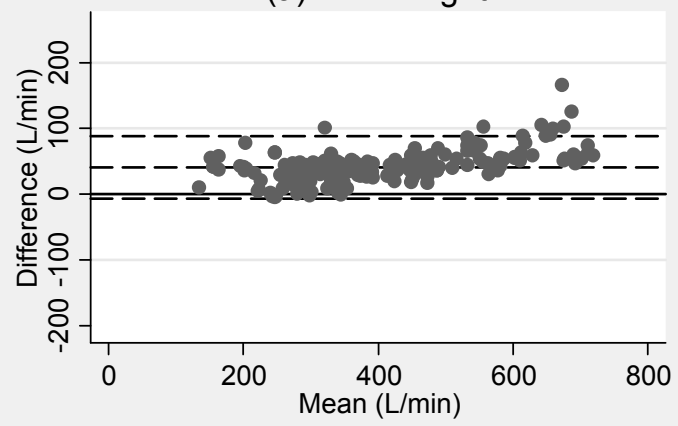

(c) SpiroUSB

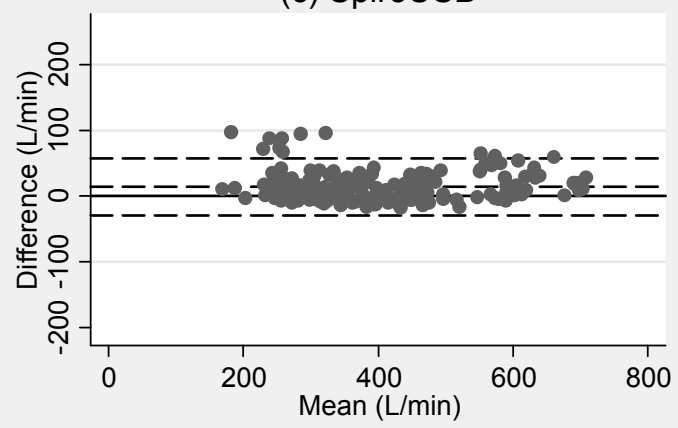

(b) Assess

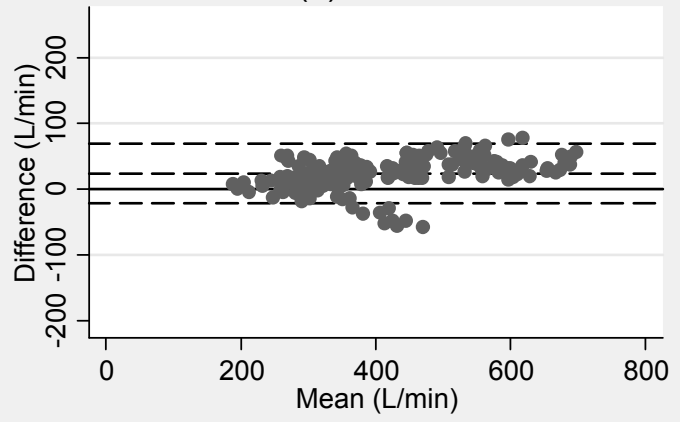

(d) Microlab

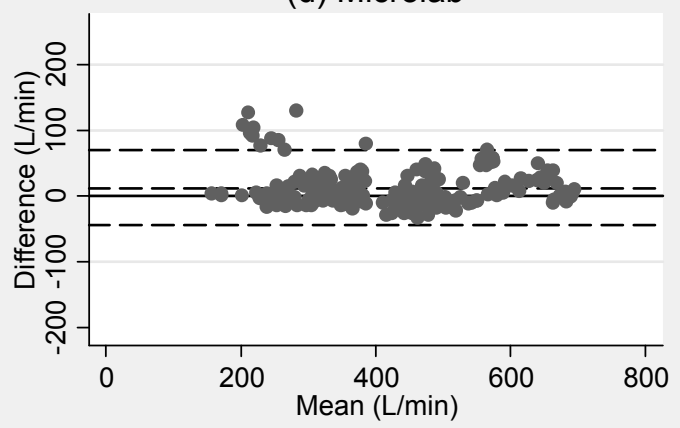

Figure 5. Forced expiratory manoeuvres by healthy volunteers: Bland-Altman graphs of the agreement in measuring peak flow $(\mathrm{L} / \mathrm{min})$ between the pneumotachograph measurement system and (a) the Mini-Wright peak flow meter, (b) the Assess peak flow meter, (c) the SpiroUSB spirometer and (d) the Microlab spirometer. The difference between two measurements (pneumotachograph alternative device) is plotted against the mean of two measurements. Solid lines indicate the lines of equality (no difference between measurements). Three dashed lines indicate the mean difference between measurements (bias) and the upper and lower 95\% limits of agreement (bias $\pm 1.96 \mathrm{SD}$ ). 
(a) Mini-Wright

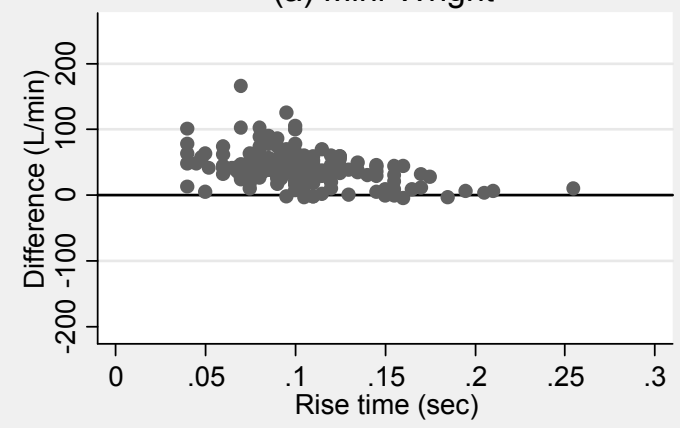

(c) SpiroUSB

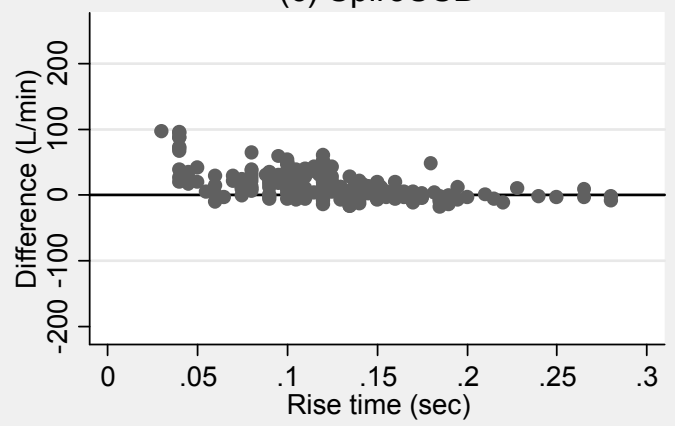

(b) Assess

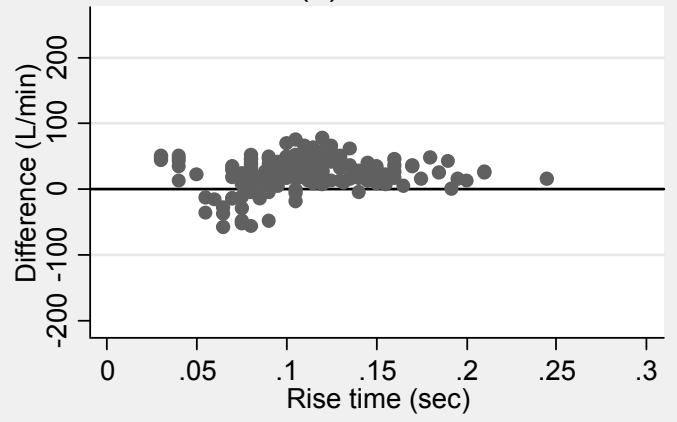

(d) Microlab

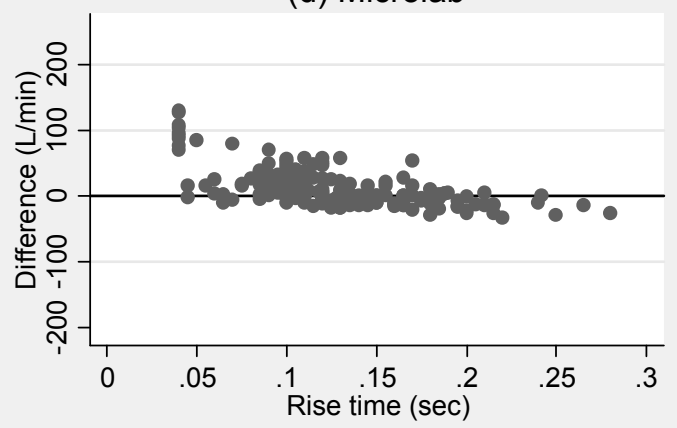

Figure 6. Forced expiratory manoeuvres by healthy volunteers: The difference (pneumotachograph alternative device) in measured peak flow (L/min) between pneumotachograph and (a) Mini-Wright peak flow meter, (b) Assess peak flow meter, (c) SpiroUSB spirometer and (d) Microlab spirometer is plotted against rise time (sec). Solid lines indicate the lines of equality (no difference between measurements). 